\title{
Longitudinal associations of the alternative and terminal pathways of complement activation with adiposity: The CODAM study
}

Citation for published version (APA):

Xin, Y., Hertle, E., van der Kallen, C. J. H., Schalkwijk, C. G., Stehouwer, C. D. A., \& van Greevenbroek, M. M. J. (2018). Longitudinal associations of the alternative and terminal pathways of complement activation with adiposity: The CODAM study. Obesity Research \& Clinical Practice, 12(3), 286-292. https://doi.org/10.1016/j.orcp.2017.11.002

Document status and date:

Published: 01/05/2018

DOI:

10.1016/j.orcp.2017.11.002

Document Version:

Publisher's PDF, also known as Version of record

\section{Document license:}

Taverne

Please check the document version of this publication:

- A submitted manuscript is the version of the article upon submission and before peer-review. There can be important differences between the submitted version and the official published version of record.

People interested in the research are advised to contact the author for the final version of the publication, or visit the DOI to the publisher's website.

- The final author version and the galley proof are versions of the publication after peer review.

- The final published version features the final layout of the paper including the volume, issue and page numbers.

Link to publication

\footnotetext{
General rights rights.

- You may freely distribute the URL identifying the publication in the public portal. please follow below link for the End User Agreement:

www.umlib.nl/taverne-license

Take down policy

If you believe that this document breaches copyright please contact us at:

repository@maastrichtuniversity.nl

providing details and we will investigate your claim.
}

Copyright and moral rights for the publications made accessible in the public portal are retained by the authors and/or other copyright owners and it is a condition of accessing publications that users recognise and abide by the legal requirements associated with these

- Users may download and print one copy of any publication from the public portal for the purpose of private study or research.

- You may not further distribute the material or use it for any profit-making activity or commercial gain

If the publication is distributed under the terms of Article 25fa of the Dutch Copyright Act, indicated by the "Taverne" license above, 
Original Article

\title{
Longitudinal associations of the alternative and terminal pathways of complement activation with adiposity: The CODAM study
}

\author{
Ying Xin, Elisabeth Hertle, Carla J.H. van der Kallen, Casper G. Schalkwijk, \\ Coen D.A. Stehouwer, Marleen M.J. van Greevenbroek*
}

Dept. of Internal Medicine, Maastricht University Medical Centre and CARIM School for Cardiovascular Diseases, Maastricht University, The Netherlands

\section{A R T I C L E I N F O}

\section{Article history:}

Received 20 June 2017

Received in revised form 25 October 2017

Accepted 3 November 2017

\section{Keywords:}

Complement

Adiposity

Human

Epidemiology

Longitudinal

\begin{abstract}
A B S T R A C T
Objective: To investigate longitudinal associations of components of the alternative ( $\mathrm{C} 3, \mathrm{C} 3 \mathrm{a}, \mathrm{Bb}$, factor D [FD], factor $\mathrm{H}[\mathrm{FH}]$, and properdin) and the terminal complement pathway ( $\mathrm{C} 5 \mathrm{a}$, sC5b-9) with adiposity. Methods: A prospective human cohort study ( $\mathrm{n}=574$ at baseline, $\mathrm{n}=489$ after 7 years follow-up) was analyzed. Generalized estimating equations were used to evaluate the longitudinal associations between complement components (standardized values) and adiposity (main outcome BMI $\left[\mathrm{kg} / \mathrm{m}^{2}\right]$ ). Multiple linear regression models were used to investigate the associations between change in complement levels and change in BMI. Analyses were adjusted for age, sex, medication and lifestyle.

Results: Over the 7-year period, baseline C3 was positively associated with BMI ( $\beta=1.72$ [95\% confidence interval (CI): $1.35 ; 2.09])$. Positive associations were also observed for $\mathrm{C} 3 \mathrm{a}(\beta=0.64[0.31 ; 0.97])$, FD ( $\beta=1.00[0.59 ; 1.42]), \mathrm{FH}(\beta=1.17[0.82 ; 1.53])$, and properdin $(\beta=0.60[0.28 ; 0.92])$, but not for $\mathrm{Bb}, \mathrm{C} 5 \mathrm{a}$ or sC5b-9. Moreover, changes in C3 $(\beta=0.52[0.34 ; 0.71])$ and FH $(\beta=0.51[0.32 ; 0.70])$ were significantly associated with changes in BMI.

Conclusions: The complement system, particularly activation of the alternative pathway, may be involved in development of adiposity. Whether individual aspects of alternative pathway activation have a causal role in human obesity, remains to be investigated.
\end{abstract}

(C) 2017 Asia Oceania Association for the Study of Obesity. Published by Elsevier Ltd. All rights

\section{Introduction}

Adipose tissue shows adaptive reactions such as expansion or atrophy in response to changes in the microenvironment (as reviewed in Ref. [1]). Obesity is an ultimate consequence of adipose tissue expansion. It is characterized by remodeling of adipocytes in size (hypertrophy) and numbers (hyperplasia) which is accompanied by local vascularization, infiltration of inflammatory cells, and enhanced extracellular matrix production (as reviewed in Ref. $[2])$.

The complement system is a complex protein network that is extensively expressed in adipose tissue [3]. It plays an important role in the innate immune system, but has in recent years also been implicated in cell and tissue homeostasis. It has three main

\footnotetext{
* Corresponding author at: Dept. of Internal Medicine, Maastricht University Medical Centre and CARIM School for Cardiovascular Diseases, Maastricht University, Universiteitssingel 50, PO Box 616, 6200 MD Maastricht, The Netherlands.

E-mail address: m.vangreevenbroek@maastrichtuniversity.nl (M.M.J. van Greevenbroek).
}

activation pathways (classical, lectin, and alternative pathway). Activation of any of these pathways will generate C 3 convertases that can cleave C3 into C3a and C3b. Activation of C3 triggers the generation of $\mathrm{C} 5$ convertases, which cleave $\mathrm{C} 5$ into $\mathrm{C} 5 \mathrm{a}$ and $\mathrm{C} 5 \mathrm{~b}$ and with subsequent activation of the main effector pathway, i.e. the terminal pathway (for details see Fig. 1) (as reviewed in Ref. [4]).

A growing body of data suggests that complement activation is involved in adipose tissue function and homeostasis. First, in vitro studies demonstrated that the C3a degradation product C3adesarg (also known as acylation stimulating protein [ASP], see Fig. 1) is able to stimulate the synthesis of triglycerides in adipocytes. As such, C3adesarg/ASP may be directly involved in adipose tissue metabolism and biology, and possibly advance differentiation of pre-adipocytes into mature adipocytes (as reviewed in Ref. [5]). In line with this, less weight gain was often observed in mice that were deficient for the C3 gene (and therefore lack not only C3 protein but also C3a and ASP), or for the receptor for C3a (C3aR) [6-8]. Thus, several lines of experimental data suggest that the C3-C3a-C3adesarg/ASP axis may causally contribute to adipocyte 


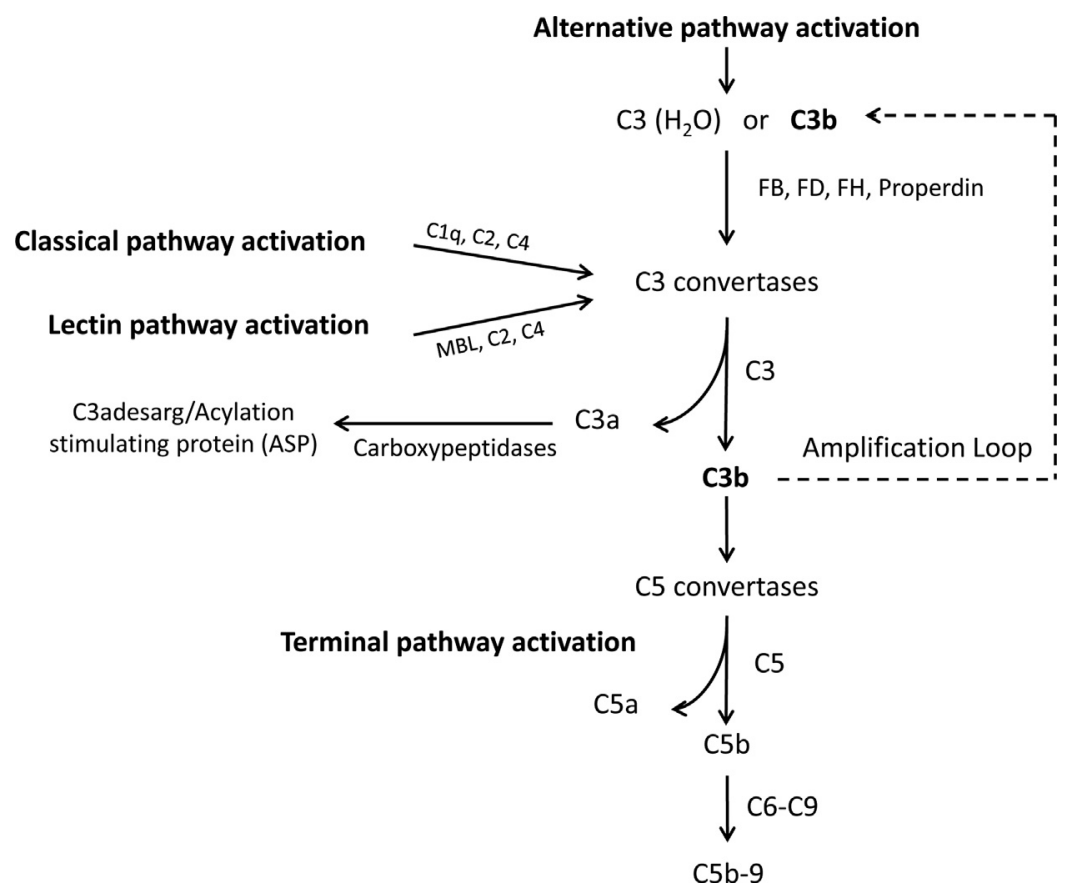

Figure 1. Activation of the complement system with focus on components that are most relevant for the current study.

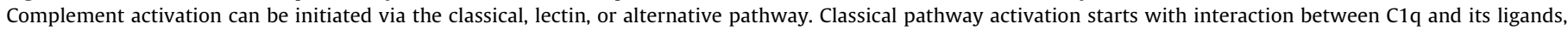

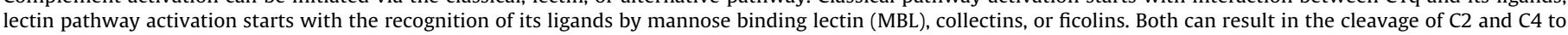

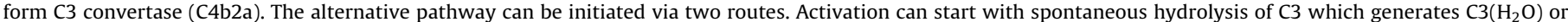

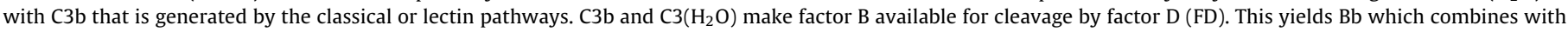

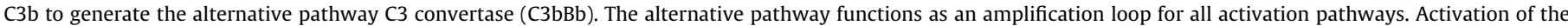

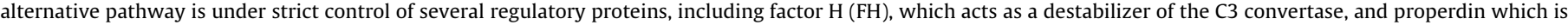

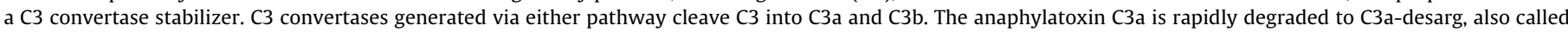

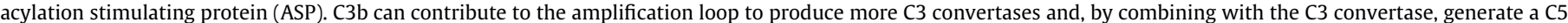
convertase, which cleaves $\mathrm{C} 5$ into $\mathrm{C} 5 \mathrm{a}$ and $\mathrm{C} 5 \mathrm{~b}$ and triggers the terminal pathway to recruit $\mathrm{C} 6, \mathrm{C} 7, \mathrm{C} 8, \mathrm{C} 9$ to form the membrane attack complex, $\mathrm{C} 5 \mathrm{~b}-9$.

biology and total body weight. The reported effects of other components of the alternative and terminal complement pathway on body weight in mouse models were less consistent. Absence of factor B did not affect body weight [8,9], while lack of properdin resulted in either increased weight gain or no consistent effect on body weight $[10,11]$. Mice deficient for the receptor for C5a (C5aR1) showed more weight gain [12], while lack of C5 or C5L2 (the alternative $\mathrm{C} 5 \mathrm{a}$ receptor that may bind both $\mathrm{C} 3 \mathrm{a}$ and $\mathrm{C} 5 \mathrm{a}$ ) did not affect body weight $[13,14]$. In addition to these experimental data, some forms of human lipodystrophy, which are characterized by progressive atrophy of subcutaneous fat, are associated with enhanced or abnormal complement activation [15]. Moreover, a substantial number of studies, mostly focusing on only one or very few complement components, reported on cross-sectional associations between circulating complement and adiposity (as reviewed in Ref. [16]). One small case-control study in elderly individuals with age-related macular degeneration reported positive cross-sectional associations with body mass index (BMI), for a larger number of complement factors [17]. Only a few studies have reported associations between changes in complement and changes in body weight in humans [18,19], and to the best of our knowledge only one study showed that complement C3 was positively associated with incident obesity [20].

Taken together, current experimental and human data suggest a link between complement and obesity that may be related to disturbed adipose tissue homeostasis. However, longitudinal human data on this relationship are still scarce. We herein investigated the longitudinal associations between complement factors of the alternative pathway [C3, C3a, Bb, factor D (FD), factor $\mathrm{H}(\mathrm{FH})$, and properdin], as well as terminal pathway (C5a and C5b-9) and adiposity in a human observational cohort.

\section{Materials and methods}

\section{Participants}

Participants of the Cohort on Diabetes and Atherosclerosis Maastricht (CODAM) were selected from a large population-based study as previously described [21]. The inclusion criteria included Caucasian descent and age $>40$ years plus one or more of the following: body mass index (BMI) $>25 \mathrm{~kg} / \mathrm{m}^{2}$; use of anti-hypertensive medication; positive family history of type 2 diabetes (T2DM); postprandial blood glucose level $>6.0 \mathrm{mmol} / \mathrm{L}$; history of gestational diabetes and/or glycosuria. At baseline 574 participants were included and 495 participants ( $>85 \%$ of baseline participants) were re-evaluated after a median follow-up of 7 [interquartile range (IQR) 6.9-7.1] years. A flowchart for inclusion of participants in the current study is shown in Supplementary Fig. S1. The study was approved by the medical ethics committee of Maastricht University. All participants gave written informed consent.

\section{Measurements}

\section{Complement factors}

After an overnight fast, blood samples were collected and stored at $-80^{\circ} \mathrm{C}$ before use. FH was measured in EDTA plasma using a commercially available ELISA kit (DuoSet, R\&D Systems, Minneapolis, MN, USA) at a $1 / 10,000$ dilution according to the manufacturer's instructions, inter-assay variation was $13.5 \%$. Measurements of other complement factors (i.e. C3, C3a, Bb, FD, properdin, C5a, sC5b9 ) were as previously described $[22,23]$. $\mathrm{C} 3 \mathrm{a}, \mathrm{Bb}$, and properdin were measured only at baseline, while C3, FD, FH, C5a, and sC5b-9 were measured at baseline and at follow-up. 
Table 1

General characteristics of the study population at baseline and follow-up.

\begin{tabular}{|c|c|c|c|}
\hline \multirow[b]{2}{*}{ Variables } & \multirow{2}{*}{$\begin{array}{l}\mathrm{N}=541^{\mathrm{a}} \\
\text { Baseline }\end{array}$} & \multicolumn{2}{|c|}{$\mathrm{N}=460^{\mathrm{b}, \mathrm{c}}$ attended follow-up } \\
\hline & & Baseline & Follow-up \\
\hline Age (years) & $59.5 \pm 7.0$ & $59.1 \pm 7.0$ & $66.2 \pm 7.0$ \\
\hline Sex (male \%) & 61 & 61 & 61 \\
\hline $\operatorname{BMI}\left(\mathrm{kg} / \mathrm{m}^{2}\right)$ & $28.6 \pm 4.4$ & $28.5 \pm 4.2$ & $28.6 \pm 4.3$ \\
\hline Waist circumference $(\mathrm{cm})$ & $99.4 \pm 12.1$ & $98.8 \pm 11.8$ & $100.5 \pm 12.1^{*}$ \\
\hline Plasma glucose (mmol/l) & $5.60(5.20-6.46)$ & $5.56(5.18-6.32)$ & $5.40(5.00-6.20)^{*}$ \\
\hline HOMA2-IR & $1.62(1.11-2.56)$ & $1.61(1.09-2.47)$ & $1.45(1.02-2.19)$ \\
\hline $\operatorname{ALT}(\mathrm{U} / \mathrm{l})$ & $22.2(17.2-28.3)$ & $22.3(17.2-28.4)$ & - \\
\hline $\operatorname{AST}(\mathrm{U} / \mathrm{l})$ & $19.9(16.4-24.2)$ & $19.9(16.3-24.2)$ & - \\
\hline GGT $(\mathrm{U} / \mathrm{l})$ & $24.0(17.0-37.8)$ & $24.0(17.0-37.0)$ & - \\
\hline $\mathrm{CRP}(\mathrm{mg} / \mathrm{l})$ & $2.07(0.94-3.96)$ & $1.89(0.90-3.70)$ & $1.98(0.91-3.92)$ \\
\hline Lipid-modifying medication (\%) & 20 & 19 & $44^{*}$ \\
\hline Glucose-lowering medication (\%) & 14 & 12 & $25^{*}$ \\
\hline Anti-hypertensive medication (\%) & 39 & 36 & $60^{*}$ \\
\hline Ever smoking (\%) & 22 & 22 & $16^{*}$ \\
\hline Cardiovascular disease (\%) & 28 & 27 & $42^{*}$ \\
\hline Type 2 diabetes (\%) & 26 & 23 & $35^{*}$ \\
\hline Physical activity $\left(10^{3} \times\right.$ METs/week) & $6.66 \pm 4.12$ & $6.73 \pm 4.18$ & $7.11 \pm 4.57$ \\
\hline Energy intake $\left(10^{3} \times \mathrm{kJ} /\right.$ day $)$ & $9.28 \pm 2.78$ & $9.39 \pm 2.80$ & $8.89 \pm 2.60^{*}$ \\
\hline $\mathrm{C} 3(\mathrm{~g} / \mathrm{l})$ & $1.01 \pm 0.16$ & $1.01 \pm 0.16$ & $1.15 \pm 0.20^{*}$ \\
\hline $\mathrm{C} 3 \mathrm{a}(\mu \mathrm{g} / \mathrm{l})$ & $59.2(49.9-72.6)$ & $58.6(49.3-71.9)$ & - \\
\hline Factor $\mathrm{Bb}(\mathrm{mg} / \mathrm{l})$ & $0.72 \pm 0.19$ & $0.71 \pm 0.19$ & - \\
\hline Factor D (mg/l) & $1.00 \pm 0.24$ & $1.00 \pm 0.24$ & $1.110 .31^{*}$ \\
\hline Factor H (mg/l) & $324.9 \pm 77.9$ & $320.8 \pm 78.1$ & $324.8 \pm 74.9$ \\
\hline Properdin (mg/l) & $6.05 \pm 1.29$ & $6.05 \pm 1.25$ & - \\
\hline $\mathrm{C} 5 \mathrm{a}(\mu \mathrm{g} / \mathrm{l})$ & $7.58 \pm 3.85$ & $7.47 \pm 3.72$ & $7.68 \pm 3.87^{*}$ \\
\hline $\mathrm{sC} 5 \mathrm{~b}-9(\mu \mathrm{g} / \mathrm{l})$ & $112.7 \pm 32.8$ & $112.9 \pm 33.1$ & $156.3 \pm 74.9^{*}$ \\
\hline
\end{tabular}

Abbreviations: BMI, body mass index; ALT, alanine aminotransferase; AST, aspartate aminotransferase; GGT, gamma-glutamyl transferase; CRP, C-reaction protein.

a 541 participants were included in GEE analyses. At baseline, data were available for all but missing for plasma glucose $(n=1)$, HOMA2-IR $(n=13)$, ALT ( $=6)$, AST ( $=6$ ), and/or for GGT $(n=1)$.

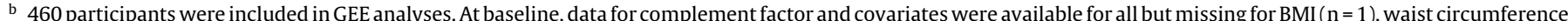

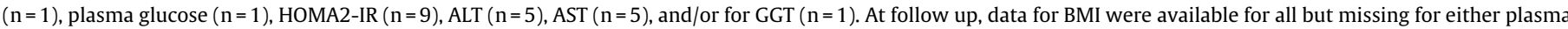

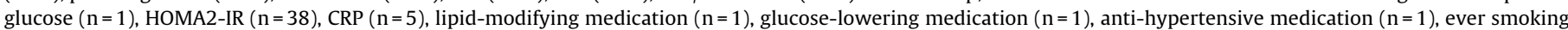

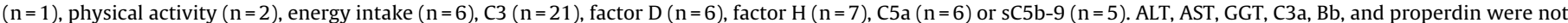
available at follow-up.

c Paired t-test and chi-square test were used for comparison of baseline and follow-up.

$p<0.05$.

\section{Adiposity and other variables}

BMI $\left(\mathrm{kg} / \mathrm{m}^{2}\right)$ and waist circumference (waist, $\mathrm{cm}$ ), as previously described [21] were used as continuous measures of adiposity. Measurements for other variables were also obtained as described before. Briefly, information on medication use (lipidmodifying, glucose-lowering, and/or anti-hypertensive yes/no), physical activity (METs/week) and total energy intake $(\mathrm{kJ} / \mathrm{d})$ was obtained using several questionnaires [21]. Fasting plasma glucose, C-reactive protein (CRP), alanine aminotransferase (ALT), aspartate aminotransferase (AST); gamma-glutamyl transferase (GGT) concentrations were obtained as previous described [24]. Prevalence of cardiovascular disease (CVD, yes/no) was defined as previously described. Impaired glucose metabolism (IGM) (yes/no) and T2DM (yes/no) were defined according to the 1999 WHO criteria as previously described [21]. All these variables were measured at baseline and at follow-up.

\section{Statistical analyses}

Variables with normal distribution are presented as mean \pm standard deviation (SD). Those with skewed distribution are presented as median (IQR) and were normalized by $\log _{2}$ transformation before any further analyses. Standardized values were calculated ([individuals' observed values - population mean]/standard deviation of the population) for the various complement components to allow direct comparison of their effect sizes. T-test and chi-square test were used to compare two groups, as indicated. All analyses were performed using IBM SPSS statistics version 22 and a 2 -tailed $P$-value of $<0.05$ was considered significant.
Generalized estimating equations (GEE) with an exchangeable correlation structure were used to evaluate the longitudinal associations between complement factors (main independent variables) and BMI or waist (outcomes). BMI was used as primary outcome in the analyses. Waist was evaluated as a secondary measure of adiposity that represents a more central accumulation of fat. Analyses were initially adjusted for stratification factors (age [years], sex [male/female]), for sampling characteristics (glucose metabolism status: IGM [yes/no], T2DM [yes/no]), and also for follow-up time (years) and time-point (baseline/follow-up). The fully adjusted model additionally included medication use (lipid-modifying, glucose-lowering, and/or anti-hypertensive, each yes/no), smoking status (current and previous tobacco smoking, yes/no), physical activity (METs/week) and energy intake (kJ/d) to control for potential confounding. Subsequently, linear regression analyses were done to investigate the associations between the within-individual changes in complement concentration and adiposity, over time.

In addition, as various glucose-lowering medications may affect body weight [25], sensitivity analyses were performed by repeating the analyses after excluding glucose-lowering medication users at baseline $(n=73)$. Also, some disease conditions may affect plasma concentrations of complement. Therefore, similar sensitivity analyses were performed in which the main analyses were repeated after excluding (1) participants with acute or chronic infections (CRP $>10 \mathrm{mg} / \mathrm{L}, \mathrm{n}=36$ ), (2) patients with a (suspected) history of autoimmune disease (defined as self-reported current chronic joint inflammation/rheumatoid arthritis or a severe intestinal disorder that lasted for the past 3 months or longer, $n=61$ ), or (3) patients with a self-reported current malignant condition/cancer $(n=19)$. 
Table 2

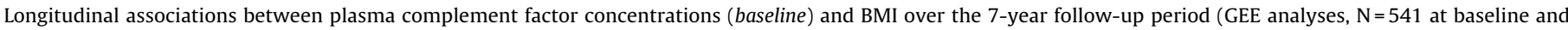
$\mathrm{N}=460$ at follow-up).

\begin{tabular}{|c|c|c|c|c|c|c|}
\hline \multirow{3}{*}{ Variables $^{\mathrm{e}}$} & \multicolumn{6}{|c|}{ Association with BMI $\left(\mathrm{kg} / \mathrm{m}^{2}\right)$} \\
\hline & \multicolumn{2}{|l|}{ Model $1^{\mathrm{a}}$} & \multicolumn{2}{|l|}{ Model $2^{\mathrm{b}}$} & \multicolumn{2}{|l|}{ Model $3^{c}$} \\
\hline & $\beta[95 \% \mathrm{CI}]$ & $P$ value & $\beta[95 \% \mathrm{Cl}]$ & $P$ value & $\beta[95 \% \mathrm{CI}]$ & $P$ value \\
\hline $\mathrm{C} 3$ & $1.96[1.61 ; 2.30]$ & $<0.001$ & $1.78[1.41 ; 2.15]$ & $<0.001$ & $1.72[1.35 ; 2.09]$ & $<0.001$ \\
\hline $\mathrm{C} 3 \mathrm{a}^{\mathrm{d}}$ & $0.83[0.18 ; 1.17]$ & $<0.001$ & $0.76[0.43 ; 1.09]$ & $<0.001$ & $0.64[0.31 ; 0.97]$ & $<0.001$ \\
\hline Factor D & $0.91[0.53 ; 1.29]$ & $<0.001$ & $1.11[0.68 ; 1.54]$ & $<0.001$ & $1.00[0.59 ; 1.42]$ & $<0.001$ \\
\hline Factor $\mathrm{H}$ & $1.46[1.11 ; 1.80]$ & $<0.001$ & $1.25[0.90 ; 1.59]$ & $<0.001$ & $1.17[0.82 ; 1.53]$ & $<0.001$ \\
\hline Properdin & $0.72[0.37 ; 1.06]$ & $<0.001$ & $0.63[0.30 ; 0.95]$ & $<0.001$ & $0.60[0.28 ; 0.92]$ & $<0.001$ \\
\hline $\mathrm{Bb}$ & $-0.26[-0.60 ; 0.08]$ & 0.135 & $-0.16[-0.50 ; 0.18]$ & 0.351 & $-0.16[-0.49 ; 0.17]$ & 0.341 \\
\hline C5a & $0.32[-0.06 ; 0.70]$ & 0.098 & $0.20[-0.18 ; 0.58]$ & 0.298 & $0.18[-0.19 ; 0.54]$ & 0.345 \\
\hline sC5b-9 & $0.19[-0.19 ; 0.58]$ & 0.322 & $0.14[-0.22 ; 0.51]$ & 0.442 & $0.10[-0.25 ; 0.45]$ & 0.580 \\
\hline
\end{tabular}

Abbreviations: BMI, body mass index; 95\% CI, 95\% confidence interval; $\beta$, regression coefficient.

a Model 1: unadjusted.

b Model 2: adjusted for baseline age, sex, baseline glucose metabolic status, follow-up time and time point.

c Model 3: Model 2 additionally adjusted for baseline medication use and lifestyle (smoking status, physical activities and energy intake).

d Data were $\log _{2}$ transformed prior to analyses.

e Data were standardized to allow direct comparison of their effect sizes.

Table 3

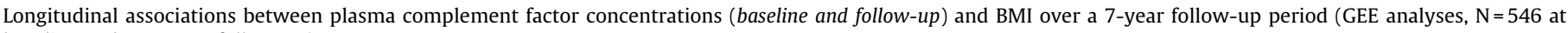
baseline and $\mathrm{N}=442$ at follow-up).

\begin{tabular}{|c|c|c|c|c|c|c|}
\hline \multirow{3}{*}{ Variables $^{\mathrm{d}}$} & \multicolumn{6}{|c|}{ Association with BMI $\left(\mathrm{kg} / \mathrm{m}^{2}\right)$} \\
\hline & \multicolumn{2}{|l|}{ Model $1^{\mathrm{a}}$} & \multicolumn{2}{|l|}{ Model $2^{\mathrm{b}}$} & \multicolumn{2}{|l|}{ Model $3^{c}$} \\
\hline & $\beta[95 \% \mathrm{CI}]$ & $P$ value & $\beta[95 \% \mathrm{CI}]$ & $P$ value & $\beta[95 \% \mathrm{CI}]$ & $P$ value \\
\hline $\mathrm{C} 3$ & $0.80[0.63 ; 0.96]$ & $<0.001$ & $1.11[0.88 ; 1.34]$ & $<0.001$ & $1.04[0.81 ; 1.26]$ & $<0.001$ \\
\hline Factor D & $0.41[-0.07 ; 0.90]$ & 0.097 & $0.53[-0.05 ; 1.11]$ & 0.071 & $0.48[-0.08 ; 1.05]$ & 0.094 \\
\hline Factor $\mathrm{H}$ & $0.97[0.75 ; 1.19]$ & $<0.001$ & $0.90[0.68 ; 1.12]$ & $<0.001$ & $0.88[0.66 ; 1.11]$ & $<0.001$ \\
\hline $\mathrm{C} 5 \mathrm{a}$ & $0.18[-0.13 ; 0.48]$ & 0.251 & $0.10[-0.20 ; 0.40]$ & 0.495 & $0.12[-0.18 ; 0.42]$ & 0.424 \\
\hline sC5b-9 & $0.10[-0.04 ; 0.24]$ & 0.151 & $0.09[-0.08 ; 0.26]$ & 0.294 & $0.08[-0.07 ; 0.24]$ & 0.291 \\
\hline
\end{tabular}

Abbreviations: BMI, body mass index; $95 \% \mathrm{CI}, 95 \%$ confidence interval; $\beta$, regression coefficient.

a Model 1: unadjusted.

b Model 2: adjusted for baseline age, sex, baseline glucose metabolic status, follow-up time and time point.

c Model 3: Model 2 additionally adjusted for medication use and lifestyle (smoking status, physical activities and energy intake) at baseline and follow-up.

d Data were standardized to allow direct comparison of their effect sizes.

\section{Results}

\section{General characteristics of the study population}

At baseline complete data were available for 541 participants $\left[59.5 \pm 7.0\right.$ years old, $61 \%$ men, BMI $28.6 \pm 4.4 \mathrm{~kg} / \mathrm{m}^{2}$; Table 1$]$. Among them, 22\% were ever-smokers, $28 \%$ had CVD, and $26 \%$ had T2DM. The percentage of lipid-modifying, glucose-lowering, and anti-hypertensive medication users was $20 \%, 14 \%, 39 \%$, respectively. Participants included in the follow-up analyses $(\mathrm{N}=460)$ had complete data for complement and other variables at baseline, and for BMI and waist at baseline and follow-up. Waist, medication use, prevalence of CVD and T2DM and concentrations of C3, FD, C5a, and sC5b-9 increased significantly during the 7-year period, while no significant changes in BMI, HOMA2-IR, CRP, and FH concentrations were observed. Habitual energy intake and plasma glucose level were lower at follow-up. The individuals without follow-up data ( $N=114$; Table S1) were at baseline slightly older, had higher FH concentration, poorer health status (more likely to have T2DM and more likely to be glucose-lowering and anti-hypertensive medication users), and had lower habitual energy intake than those with follow-up data.

Longitudinal associations between plasma complement and adiposity over a 7-year follow-up period

A significant positive correlation between baseline C3 concentration (standardized value) and BMI (in $\mathrm{kg} / \mathrm{m}^{2}$, baseline and follow-up) was observed in the unadjusted model (Model 1;
$\mathrm{N}=541$ at baseline, $\mathrm{N}=460$ at follow-up; Table 2). This association remained basically unchanged in the minimally adjusted model (Model 2) and in the fully adjusted model (Model 3, C3 $\beta=1.72$ [95\% confidence interval (CI): $1.35 ; 2.09]$ ]). Thus $1 \mathrm{SD}$ higher baseline concentration of $\mathrm{C} 3$ was associated with, on average, $1.72 \mathrm{~kg} / \mathrm{m}^{2}$ higher BMI over the 7-year period. Positive associations were also observed for other factors of the alternative pathway: $\mathrm{C} 3 \mathrm{a}(\beta=0.64$ [95\% CI 0.31; 0.97]), FD ( $\beta=1.00$ [95\% CI 0.59; 1.42$]), \mathrm{FH}(\beta=1.17$ $[95 \%$ CI $0.82 ; 1.53])$, and properdin $(\beta=0.60[95 \%$ CI $0.28 ; 0.92])$. In contrast, the associations of $\mathrm{Bb}(\beta=-0.16$ [95\% $\mathrm{CI}-0.49 ; 0.17])$, which is also part of the alternative pathway, and $C 5 a(\beta=0.18[95 \%$ $\mathrm{CI}-0.19 ; 0.54])$ and sC5b-9 ( $\beta=0.10$ [95\% CI $-0.25 ; 0.45])$, which are part of the terminal pathway, with BMI were not significant.

Next, follow-up data of complement concentrations (available for $\mathrm{C} 3, \mathrm{FD}, \mathrm{FH}, \mathrm{C} 5 \mathrm{a}$, and $\mathrm{C} 5 \mathrm{~b}-9$ ) were added to the GEE model $(\mathrm{N}=546$ at baseline and $\mathrm{N}=442$ at follow-up; Table 3$)$. As for the GEE analyses with complement factors measured only at baseline, positive associations were observed for the markers of the alternative pathway (Model 1, Model 2), which were significant for $\mathrm{C} 3$ and $\mathrm{FH}$, but not for FD. The regression coefficients were basically unchanged in the fully adjusted models (C3: $\beta=1.04[95 \% \mathrm{CI}$ $0.81 ; 1.26$ ], $\mathrm{FH}: \beta=0.88$ [95\% CI 0.66; 1.11], FD: $\beta=0.48$ [95\% CI $-0.08 ; 1.05]$ ). The associations for $\mathrm{C} 5 \mathrm{a}$ and sC5b-9 were, again, nonsignificant (Model 1, Model 2). The regression coefficients remained basically unchanged in the fully adjusted models ( $\mathrm{C} 5 \mathrm{a}: \beta=0.12[95 \%$ $\mathrm{CI}-0.18 ; 0.42$ ], sC5b-9: $\beta=0.08$ [95\% CI $-0.070 .24]$ ). When waist instead of BMI was used as a measure of adiposity, most associations were consistent. A few additional statistically significant associations were observed in the unadjusted models for waist that 
Table 4

Linear regression analyses between change in complement factor and change in BMI (follow-up-baseline) $\mathrm{N}=429$.

\begin{tabular}{|c|c|c|c|c|c|c|}
\hline \multirow{3}{*}{ Variables $^{\mathrm{d}}$} & \multicolumn{6}{|c|}{ Association with $\Delta \mathrm{BMI}\left(\mathrm{kg} / \mathrm{m}^{2}\right)$} \\
\hline & \multicolumn{2}{|l|}{ Model $1^{\mathrm{a}}$} & \multicolumn{2}{|l|}{ Model $2^{\mathrm{b}}$} & \multicolumn{2}{|l|}{ Model $3^{c}$} \\
\hline & $\beta[95 \% \mathrm{CI}]$ & $P$ value & $\beta[95 \% \mathrm{CI}]$ & $P$ value & $\beta[95 \% \mathrm{CI}]$ & $P$ value \\
\hline$\Delta \mathrm{C} 3$ & $0.58[0.40 ; 0.77]$ & $<0.001$ & $0.58[0.39 ; 0.77]$ & $<0.001$ & $0.52[0.34 ; 0.71]$ & $<0.001$ \\
\hline$\Delta$ Factor D & $0.10[-0.09 ; 0.30]$ & 0.303 & $0.17[-0.04 ; 0.37]$ & 0.108 & $0.12[-0.09 ; 0.33]$ & 0.246 \\
\hline$\Delta$ Factor $\mathrm{H}$ & $0.52[0.33 ; 0.71]$ & $<0.001$ & $0.53[0.34 ; 0.72]$ & $<0.001$ & $0.51[0.32 ; 0.70]$ & $<0.001$ \\
\hline$\Delta \mathrm{C} 5 \mathrm{a}$ & $-0.04[-0.23 ; 0.15]$ & 0.686 & $-0.03[-0.23 ; 0.16]$ & 0.745 & $-0.00[-0.20 ; 0.19]$ & 0.987 \\
\hline$\Delta \mathrm{sC} 5 \mathrm{~b}-9$ & $0.10[-0.09 ; 0.30]$ & 0.292 & $0.12[-0.08 ; 0.32]$ & 0.233 & $0.12[-0.07 ; 0.32]$ & 0.213 \\
\hline
\end{tabular}

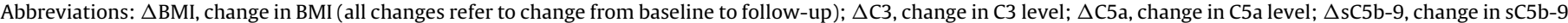
level; $\Delta$ factor $\mathrm{D}$, change in factor $\mathrm{D}$ level; $\Delta$ factor $\mathrm{H}$, change in factor $\mathrm{H}$ level; $\beta$, regression coefficient.

a Model 1: unadjusted.

b Model 2: adjusted for baseline age, sex, baseline glucose metabolic status, follow-up time.

c Model 3: Model 2 additionally adjusted for medication use and lifestyles (smoking status, physical activities and energy intake) at baseline and follow-up.

d Data were standardized to allow direct comparison of their effect sizes.

were not seen with BMI, i.e. a significant inverse association for baseline $\mathrm{Bb}(\beta=-1.11[95 \% \mathrm{CI}-2.13 ;-0.09])$, and significant positive associations for FD $(\beta=1.69[95 \% \mathrm{CI} 0.16 ; 3.21])$ and sC5b-9 $(\beta=0.74[95 \% \mathrm{CI} 0.11 ; 1.37])$ at baseline and follow-up. These associations all disappeared in the minimally and fully adjusted models (Tables S2, S3).

By performing the GEE analyses, we obtain an indication of the overall longitudinal association between complement factors and adiposity, which consists of a combination of associations within and between individuals. To further evaluate the associations within individuals, linear regression was used to evaluate the associations between changes in complement factors and changes in adiposity, over time.

As shown in Table 4 , change $(\Delta)$ in $\mathrm{C} 3$ (baseline to follow-up) was positively associated with $\triangle \mathrm{BMI}$ in the unadjusted and minimally adjusted model, and remained virtually unchanged in the fully adjusted model $(\triangle C 3: \beta=0.52[95 \% \mathrm{CI} 0.34 ; 0.71] \mathrm{N}=429)$. $\mathrm{A} 1$ SD larger $\Delta C 3$ was associated with $0.52 \mathrm{~kg} / \mathrm{m}^{2}$ larger $\Delta$ BMI. A positive association was also observed for $\mathrm{FH}$ (Model 3, $\Delta \mathrm{FH}: \beta=0.51$ [95\% CI 0.32;0.70]). The associations of changes in the other complement factors with $\triangle$ BMI were non-significant (Model 3, $\triangle \mathrm{FD}$ : $\beta=0.12$ [95\% CI $-0.09 ; 0.33$ ], $\Delta \mathrm{C} 5 \mathrm{a}: \beta=-0.00$ [95\% CI $-0.20 ; 0.19]$, $\Delta$ sC5b-9: $\beta=0.12$ [95\% CI $-0.07 ; 0.32])$. When waist instead of BMI was used as a measure of adiposity, again, similar results were observed (Table S4).

\section{Additional analyses}

In the sensitivity analyses, all analyses were repeated after excluding participants using glucose-lowering medication at baseline. This did not materially change the above results (Tables S5-S7). Also when participants with acute or chronic infections, with a (suspected) history of autoimmune disease, or with a selfreported current malignant condition/cancer, were excluded from the analyses, the results remained similar to what was observed in the main analyses (data not shown).

\section{Discussion}

In this Caucasian cohort we investigated the longitudinal associations of systemic factors of complement and complement activation with development of obesity, as represented by progression of adiposity. Our study has three main findings. First, over the 7-year follow-up period, higher baseline concentrations of C3, C3a, $\mathrm{FD}, \mathrm{FH}$, and properdin, but not factor $\mathrm{Bb}$, were associated with more adiposity, and these associations remained for $\mathrm{C} 3$ and $\mathrm{FH}$, but not for FD, after additionally considering their concentrations at followup. Second, greater changes in $\mathrm{C} 3$ and $\mathrm{FH}$ were positively associated with greater changes in BM and waist. Third, no associations were observed between components of the terminal pathway, i.e. C5a and sC5b-9, and adiposity.

Previously-published studies mainly showed positive crosssectional association of individual complement components including C3 [26,27], Bb [17], FD [28,29], and FH [17,30] - with human adiposity. However, until now, systematic evaluations of the associations of complement system with adiposity within human cohorts have been scarce. Also, the number of studies that provide longitudinal data is limited. Moreover, human information on the relation of properdin, an important regulator for alternative pathway, with adiposity was lacking, while associations for C5a and sC5b-9 were evaluated only in very small cross-sectional studies [17].

The positive association of $\mathrm{C} 3$ we observed with adiposity over time is in line with the results in previous cross-sectional and prospective studies $[20,26,27]$. These human data are also supported by the findings of less weight gain observed in $\mathrm{C} 3$ - and C3aR-deficient mice [6,7]. Indeed, we also observed that C3a, the cleavage product of $\mathrm{C} 3$, was positively associated with adiposity, albeit weaker than C3. This weaker association may, at least partly, be explained by the lower concentration and shorter half-life of C3a in plasma (as reviewed in Ref. [31]).

Over the 7-year follow-up period, a positive association was also observed between adiposity and FD, the rate-limiting protease of the alternative complement pathway activation. Noteworthily, changes in FD were not associated with changes in adiposity. Thus, the positive association between FD and adiposity appeared to reflect inter-individual associations that remained consistent over time rather than within-individual effects. Existing mouse models of obesity suggest that the relation between FD and obesity in mice may differ from that in man because, in contrast to the positive association between FD and obesity in man, several obese mouse models have very low concentrations of FD [32,33]. Notwithstanding these apparent differences between man and mice, the observation that FD gene knock-out in mice did not affect body weight [34] seems to be consistent with the current lack of an association between FD and adiposity within individuals. The strong between-individual and the absence of within-individual associations suggest a complex relation between FD and adiposity. We did not observe any associations between the activated complement factor, $\mathrm{Bb}$, and adiposity. This was consistent with the results of the above-mentioned cross-sectional study and previous mouse models $[8,9,17]$.

FH and properdin are two important regulators of alternative complement pathway activation. FH acts as an inhibitor by dissociating the $\mathrm{C} 3$ convertase, whereas properdin can function as a stabilizer of this convertase which results in prolonged activation (as reviewed in Ref. [35]) [36]. Despite these opposite biological functions, systemic concentrations of both $\mathrm{FH}$ and properdin 
could reflect alternative pathway activation: properdin via a direct effect on prolonged activation and $\mathrm{FH}$ as a compensatory response to enhanced alternative pathway activation. Herein, we report positive associations for $\mathrm{FH}$ and properdin with adiposity. This corroborates and expands the previous cross-sectional findings of a positive association between $\mathrm{FH}$ and obesity $[17,30]$. Until now, no information was available for properdin in human obesity and effects of properdin in mouse models were not fully consistent. Properdin-deficient mice showed more weight gain on a high fat diet [10], while no effect on body weight was observed in properdin-deficient male mice on an $\mathrm{Ldlr}^{-/}$- background [11]. Our current data add evidence for a potential role of properdin in human adipose tissue metabolism and obesity, but possible underlying mechanisms remain to be identified. Effect-sizes for FH were slightly larger than for properdin. This can be explained by several phenomena, including higher plasma concentration of $\mathrm{FH}$ and differences in measurement error and/or biological variability, but also to different functional properties since they have different binding sites with the activated C3 fragment (as reviewed in Ref. [37]), as well as to actual differences in their mutual effects on human adiposity.

In contrast to the above-mentioned results for the alternative pathway, the terminal pathway (as represented by C5a and sC5b9 ) was not longitudinally associated with adiposity. This is in line with the cross-sectional study mentioned above [17]. It is also in line with experimental data that showed that absence of $\mathrm{C} 5$ in mice, which basically abolishes the terminal pathway, did not affect weight gain [13]. Effects of absence of the receptors for terminal pathway activation products showed mixed results since C5L2 knock-out did not affect body weight [14] whereas more weight gain was observed in C5aR1 deficient mice [12].

Taken together, our data suggest that, of the various components and regulators of the alternative and terminal pathway of complement activation we evaluated, it is primarily the C3C3a-C3adesarg/ASP axis that may contribute to the development of obesity in humans. A possible explanation for the association between C3-C3a-C3adesArg/ASP axis activation and obesity lies in its proposed effects on lipid accumulation and adipocyte differentiation. Activation of the C3-C3a-C3adesArg/ASP axis starts by cleavage of $\mathrm{C} 3$ by $\mathrm{C} 3$ convertase under the control of $\mathrm{FD}, \mathrm{FH}$, and properdin. In this process $\mathrm{C} 3 \mathrm{a}$ is generated, which is unstable and can be rapidly cleaved into C3adesArg/ASP. Thus, C3adesArg/ASP is a primary end-product of this axis. Previous experimental studies showed that C3adesarg/ASP was implicated in lipid metabolism via promotion of the uptake adipocyte fatty acid by adipocytes and stimulation of triglyceride synthesis in adipocytes (as reviewed in Ref. [5]). Via such effects, C3adesArg/ASP may contribute to body fat storage. It has also been shown that chylomicrons, the intestinal lipoproteins that are produced upon food ingestion, can induce the production and activation of $\mathrm{C} 3$ and $\mathrm{C} 3 \mathrm{a}$ by adipocytes, in vitro[38]. Promotion and activation of C3-C3a-C3adesArg/ASP axis by chylomicrons may as such contribute to the development of high-fat-diet-induced obesity. Moreover, gain or loss of function of Factor D in adipocytes, in vitro, was also reported to have an effect on lipid accumulation and cell differentiation via the activation of C3-C3a-C3adesarg/ASP axis [39]. In addition to its role as stabilizer of the $\mathrm{C} 3$ convertase, properdin might also affect adipocyte metabolism via other routes. By itself, properdin did not directly affect adipocyte biology. Rather, it inhibited insulin-induced fatty acid uptake, which was independent of C3adesarg/ASP [10]. Moreover, properdin is homologous to thrombospondin-1, which is expressed in adipose tissue and may affect pre-adipocytes differentiation [40] (as reviewed in Ref. [41]).

The main strength of our present study is that we are the first to investigate the longitudinal association of adiposity and obesity with complement activation, and were able to perform a compre- hensive analysis that extends beyond the complement components usually measured in human cohorts. Another key strength of this study is the comprehensive adjustment for potential confounders. Nevertheless, some limitations should be highlighted as well. Firstly, selection of the study population may limit generalizability. Besides, the BMI of our study population was on average $\left(28.6 \pm 4.4 \mathrm{~kg} / \mathrm{m}^{2}\right)$ slightly elevated, which may also weaken the generalizability of our findings. However, considering the wide range of BMI (from 18.22 to $47.37 \mathrm{~kg} / \mathrm{m}^{2}$ ) at baseline, and the fact that we still had enough cases of participants (70\%) with normal BMI and overweight $\left(\mathrm{BMI}<30 \mathrm{~kg} / \mathrm{m}^{2}\right)$, CODAM does represent the middle-aged to older Caucasian population with moderately increased risk of T2DM and CVD. Other limitations of our study are the relatively small sample size, the fact that $15 \%$ of the original cohort was lost-to-follow-up, and the lack of information on C3a, $\mathrm{Bb}$, and properdin at follow-up. However, the fact that our results are consistent with previous data, substantiates our current observations. In addition, we cannot completely exclude the possibility of reversed causality. In other words, because of the intricate association between complement, low-grade inflammation and obesity in adipose tissue, it is not easy to disentangle the order of events, in this observational study with two available time-points. However, absence of complement genes in several mouse models did affect body weight. This suggests that the associations we report here may, at least in part, be due to effects of complement on human obesity, rather than the reverse. We do acknowledge that the reverse may occur as well contributing to a vicious, potentially accelerating cycle of obesity and complement activation in adipose tissue. Further experimental data are needed to pin-point the exact mechanisms that underlie the observed associations.

In conclusion, in this study we evaluated a broad range of factors and regulators of the alternative and terminal pathways of complement activation in humans and showed that primarily activation of C3-C3a-C3adesarg/ASP axis pathway might contribute to the development of adiposity and eventually obesity, possibly via effects on fat storage in the adipocytes. Notably, in our analyses we focused on development of adiposity and obesity rather than on adipose tissue function. Our current data therefore do not exclude that other aspects of complement activation in adipose tissue may act as relevant potential contributors to adipose tissue dysfunction in individuals with overweightness or obesity. To further extend our knowledge on the intricate relation between the complement activation and human obesity, more human prospective and intervention studies with detailed information on complement activation and detailed phenotyping of adipose tissue and metabolism are needed.

\section{Conflicts of interest}

The authors declared no conflict of interest.

\section{Acknowledgements}

Part of this work was supported by grants of the Netherlands Organization for Scientific Research (940-35-034) and the Dutch Diabetes Research Foundation (98.901) and Dutch Heart Foundation (NHS2010B194); Ying Xin is supported by the Chinese Scholarship Council (201507040040).

\section{Appendix A. Supplementary data}

Supplementary data associated with this article can be found, in the online version, at https://doi.org/10.1016/j.orcp.2017.11.002. 


\section{References}

[1] Scherer PE. The multifaceted roles of adipose tissue-therapeutic targets for diabetes and beyond: the 2015 banting lecture. Diabetes 2016;65:1452-61.

[2] Sun K, Kusminski CM, Scherer PE. Adipose tissue remodeling and obesity. J Clin Invest 2011:121:2094-101.

[3] Gabrielsson BG, Johansson JM, Lonn M, Jernas M, Olbers T, Peltonen M, et al. High expression of complement components in omental adipose tissue in obese men. Obes Res 2003;11:699-708.

[4] Ricklin D, Hajishengallis G, Yang K, Lambris JD. Complement: a key system for immune surveillance and homeostasis. Nat Immunol 2010;11:785-97.

[5] Vlaicu SI, Tatomir A, Boodhoo D, Vesa S, Mircea PA, Rus H. The role of complement system in adipose tissue-related inflammation. Immunol Res 2016:1-12.

[6] Murray I, Havel PJ, Sniderman AD, Cianflone K. Reduced body weight, adipose tissue, and leptin levels despite increased energy intake in female mice lacking acylation-stimulating protein. Endocrinology 2000;141:1041-9.

[7] Xia Z, Sniderman AD, Cianflone K. Acylation-stimulating protein (ASP) deficiency induces obesity resistance and increased energy expenditure in ob/ob mice. J Biol Chem 2002;277:45874-9.

[8] Paglialunga S, Fisette A, Yan Y, Deshaies Y, Brouillette JF, Pekna M, et al Acylation-stimulating protein deficiency and altered adipose tissue in alternative complement pathway knockout mice. Am J Physiol Endocrinol Metab 2008;294:E521-9.

[9] Malik TH, Cortini A, Carassiti D, Boyle JJ, Haskard DO, Botto M. The alternative pathway is critical for pathogenic complement activation in endotoxinand diet-induced atherosclerosis in low-density lipoprotein receptor-deficient mice. Circulation 2010;122:1948-56.

[10] Gauvreau D, Roy C, Tom FQ, Lu H, Miegueu P, Richard D, et al. A new effector of lipid metabolism: complement factor properdin. Mol Immunol 2012;51:73-81.

[11] Steiner T, Francescut L, Byrne S, Hughes T, Jayanthi A, Guschina I, et al. Protective role for properdin in progression of experimental murine atherosclerosis. PLoS One 2014;9:e92404.

[12] Phieler J, Chung KJ, Chatzigeorgiou A, Klotzsche-von Ameln A, Garcia-Martin R, Sprott D, et al. The complement anaphylatoxin C5a receptor contributes to obese adipose tissue inflammation and insulin resistance. J Immunol 2013;191:4367-74.

[13] Pritchard MT, McMullen MR, Stavitsky AB, Cohen JI, Lin F, Medof ME, et al. Differential contributions of C3, C5, and decay-accelerating factor to ethanolinduced fatty liver in mice. Gastroenterology 2007;132:1117-26.

[14] Paglialunga S, Schrauwen P, Roy C, Moonen-Kornips E, Lu H, Hesselink MK, et al. Reduced adipose tissue triglyceride synthesis and increased muscle fatty acid oxidation in C5L2 knockout mice. J Endocrinol 2007;194:293-304.

[15] Savage DB, Semple RK, Clatworthy MR, Lyons PA, Morgan BP, Cochran EK, et al. Complement abnormalities in acquired lipodystrophy revisited. J Clin Endocrinol Metab 2009:94:10-6.

[16] Hertle E, Stehouwer CD, van Greevenbroek MM. The complement system in human cardiometabolic disease. Mol Immunol 2014;61:135-48.

[17] Reynolds R, Hartnett ME, Atkinson JP, Giclas PC, Rosner B, Seddon JM. Plasma complement components and activation fragments: associations with agerelated macular degeneration genotypes and phenotypes. Invest Ophthalmol Vis Sci 2009;50:5818-27.

[18] Hernandez-Mijares A, Banuls C, Bellod L, Jover A, Sola E, Morillas C, et al. Effect of weight loss on C3 and C4 components of complement in obese patients. Eur J Clin Invest 2012;42:503-9.

[19] Pomeroy C, Mitchell J, Eckert E, Raymond N, Crosby R, Dalmasso AP. Effect of body weight and caloric restriction on serum complement proteins, including factor D/adipsin: studies in anorexia nervosa and obesity. Clin Exp Immunol 1997; 108:507-15.

[20] Engstrom G, Hedblad B, Janzon L, Lindgarde F. Weight gain in relation to plasma levels of complement factor 3: results from a population-based cohort study. Diabetologia 2005;48:2525-31

[21] van Greevenbroek MM, Arts IC, van der Kallen CJ. Dagnelie PC, Ferreira I, Jansen $\mathrm{E}$, et al. Complement $\mathrm{c} 3$ is inversely associated with habitual intake of provitamin A but not with dietary fat, fatty acids, or vitamin $\mathrm{E}$ in middle-aged to older white adults and positively associated with intake of retinol in middle-aged to older white women. J Nutr 2014;144:61-7.
[22] Hertle E, Arts IC, van der Kallen CJ, Feskens EJ, Schalkwijk CG, Stehouwer $\mathrm{CD}$, et al. The alternative complement pathway is longitudinally associated with adverse cardiovascular outcomes. The CODAM study. Thromb Haemost 2016:115:446-57.

[23] Hertle E, van Greevenbroek MM, Arts IC, van der Kallen CJ, Feskens EJ Schalkwijk CG, et al. Complement activation products C5a and sC5b-9 are associated with low-grade inflammation and endothelial dysfunction, but not with atherosclerosis in a cross-sectional analysis: the CODAM study. Int J Cardiol 2014;174:400-3.

[24] Wlazlo N, van Greevenbroek MM, Ferreira I, Jansen EH, Feskens EJ, van der Kallen CJ, et al. Activated complement factor 3 is associated with liver fat and liver enzymes: the CODAM study. Eur J Clin Invest 2013;43:679-88.

[25] Kostev K, Pscherer S, Rist R, Busch S, Scheerer MF. Changes in glycemic control and body weight after initiation of dapagliflozin or basal insulin supported oral therapy in type 2 diabetes. J Diabetes Sci Technol 2017;11:590-6.

[26] Onat A, Hergenc G, Can G, Kaya Z, Yuksel H. Serum complement C3: a determinant of cardiometabolic risk, additive to the metabolic syndrome, in middle-aged population. Metabolism 2010;59:628-34.

[27] Hernandez-Mijares A, Jarabo-Bueno MM, Lopez-Ruiz A, Sola-Izquierdo E, Morillas-Arino C, Martinez-Triguero ML. Levels of C3 in patients with severe, morbid and extreme obesity: its relationship to insulin resistance and different cardiovascular risk factors. Int J Obes (Lond) 2007:31:927-32.

[28] Klein-Wieringa IR, van der Linden MP, Knevel R, Kwekkeboom JC, van Beelen E, Huizinga TW, et al. Baseline serum adipokine levels predict radiographic progression in early rheumatoid arthritis. Arthritis Rheum 2011:63:2567-74.

[29] Abu-Farha M, Behbehani K, Elkum N. Comprehensive analysis of circulating adipokines and hsCRP association with cardiovascular disease risk factors and metabolic syndrome in Arabs. Cardiovasc Diabetol 2014;13:76.

[30] Moreno-Navarrete JM, Martinez-Barricarte R, Catalan V, Sabater M, GomezAmbrosi J, Ortega FJ, et al. Complement factor $\mathrm{H}$ is expressed in adipose tissue in association with insulin resistance. Diabetes 2010;59:200-9.

[31] Ricklin D, Lambris JD. Complement-targeted therapeutics. Nat Biotechnol 2007;25:1265-75

[32] Flier JS, Cook KS, Usher P, Spiegelman BM. Severely impaired adipsin expression in genetic and acquired obesity. Science 1987;237:405-8.

[33] Lowell BB, Napolitano A, Usher P, Dulloo AG, Rosen BS, Spiegelman BM, et al. Reduced adipsin expression in murine obesity: effect of age and treatment with the sympathomimetic-thermogenic drug mixture ephedrine and caffeine. Endocrinology 1990:126:1514-20.

[34] Xu Y, Ma M, Ippolito GC, Schroeder Jr HW, Carroll MC, Volanakis JE. Complement activation in factor D-deficient mice. Proc Natl Acad Sci U S A 2001;98:14577-82.

[35] Rodriguez de Cordoba S, Esparza-Gordillo J, Goicoechea de Jorge E, Lopez-Trascasa M, Sanchez-Corral P. The human complement factor $\mathrm{H}$ : functional roles, genetic variations and disease associations. Mol Immunol 2004:41:355-67.

[36] Spitzer D, Mitchell LM, Atkinson JP, Hourcade DE. Properdin can initiate complement activation by binding specific target surfaces and providing a platform for de novo convertase assembly. J Immunol 2007;179:2600-8.

[37] Kouser L, Abdul-Aziz M, Nayak A, Stover CM, Sim RB, Kishore U. Properdin and factor h: opposing players on the alternative complement pathway see-saw. Front Immunol 2013;4:93.

[38] Fujita T, Fujioka T, Murakami T, Satomura A, Fuke Y, Matsumoto K. Chylomicron accelerates $\mathrm{C} 3$ tick-over by regulating the role of factor $\mathrm{H}$, leading to overproduction of acylation stimulating protein. J Clin Lab Anal 2007;21:14-23.

[39] Song NJ, Kim S, Jang BH, Chang SH, Yun UJ, Park KM, et al. Small moleculeinduced complement factor D (sdipsin) promotes lipid accumulation and adipocyte differentiation. PLoS One 2016;11:e0162228.

[40] Goundis D, Reid KB. Properdin, the terminal complement components, thrombospondin and the circumsporozoite protein of malaria parasites contain similar sequence motifs. Nature 1988;335:82-5.

[41] Pattrick M, Luckett J, Yue L, Stover C. Dual role of complement in adipose tissue. Mol Immunol 2009;46:755-60. 